\title{
Activation of the G Protein-Coupled Estrogen Receptor Prevented the Development of Acute Colitis by Protecting the Crypt Cell
}

\author{
Qian Wang, ${ }^{1}$ Zhao Li, Kaixuan Liu, Jianbo Liu, Shiquan Chai, ${ }^{2}$ Guanyu Chen, Shuyu Wen, \\ Tian Ming, Jiayi Wang, Yuntao Ma, Honghui Zeng, Chuanyong Liu, and Bing Xue \\ Department of Physiology and Pathophysiology, School of Basic Medical Science, Cheeloo College of Medicine, Shandong \\ University, Jinan, China (Q.W., Z.L., K.L., J.L., S.C., G.C., S.W., T.M., H.Z., C.L., B.X.) and Second Clinical Medical College, \\ Lanzhou University, Lanzhou, China (Y.M.)
}

Received July 14, 2020; accepted October 5, 2020

\begin{abstract}
G protein-coupled estrogen receptor (GPER) might be involved in ulcerative colitis (UC), but the direct effect of GPER on UC is still unclear. We used male C57BL/6 mice to establish the acute colitis model with administration of dextran sulfate sodium and explored the effect of GPER on acute colitis and its possible mechanism. The selective GPER agonist G-1 inhibited weight loss and colon shortening and decreased the disease activity index for colitis and histologic damage in mice with colitis. All of these effects were prevented by a selective GPER blocker. G-1 administration prevented the dysfunction of tight junction protein expression and goblet cells in colitis model and thus inhibited the increase of mucosal permeability in colitissuffering mice significantly. GPER activation reduced expression of glucose-regulating peptide-78 and anti-CCAAT/ enhancer-binding protein homologous protein and attenuated the three arms of the unfolded protein response in colitis. G-1 therapy inhibited the increase of cleavage caspase-3- and TUNEL-positive cells in colonic crypts in the colitis model, increased the number of Ki67- and
\end{abstract}

bromodeoxyuridine-positive cells in crypts, and reversed the decrease of cyclin D1 and cyclin B1 expression in colitis, indicating its protective effect on crypt cells. In cultured CCD841 cells, G-1 treatment fought against cell injury induced by endoplasmic reticulum stress. These findings demonstrate that GPER activation prevents colitis by protecting the colonic crypt cells, which are associated with inhibition of endoplasmic reticulum stress.

\section{SIGNIFICANCE STATEMENT}

We demonstrate that $G$ protein-coupled estrogen receptor (GPER) activation prevents dextran sulfate sodium-induced acute colitis by protecting the crypt cells, showing that it inhibited the crypt cell apoptosis and protected proliferation of crypt cells, which resulted in protection of the intestinal mucosal barrier. This protective effect was achieved (at least in part) by inhibiting endoplasmic reticulum stress. Mucosal healing is regarded as a key therapeutic target for colitis, and GPER is expected to become a new therapeutic target for colitis.

\section{Introduction}

Ulcerative colitis (UC) is one of two major types of inflammatory bowel disease (IBD), which leads to chronic, recurrent, and intermittent inflammatory mucosal lesions of

This work was supported by the National Natural Science Foundation of China [Grant 31771278], the Natural Science Foundation of Shandong Province [Grant ZR2016HM51], and Technology Research and Development Program of Shandong Province [Grant 2017GSF218011].

${ }^{1}$ Current affiliation: Department of Pathology, Jining People's Hospital, Jining, China.

${ }^{2}$ Current affiliation: Department of Anesthesiology, Shangrao People's Hospital, Jiangxi, China.

https://doi.org/10.1124/jpet.120.000216. the distal colon, characterized by hematochezia, diarrhea, weight loss, and abdominal pain (Adams and Bornemann, 2013). A paper published in 2018 showed that the highest reported prevalence values of UC were in Europe (5.05 per 100,000 in Norway) and North America (2.86 per 100,000 in the United States). The incidence rate was also accelerating in the newly industrialized countries of Asia, South America, and Africa in the 21st century ( $\mathrm{Ng}$ et al., 2018). In addition to antiinflammatory and immunomodulatory therapies, mucosal healing, which is closely related to long-term remission and prevention of recurrence, might be another goal of IBD therapy (Bernstein, 2015).

ABBREVIATIONS: ATF6, activating transcription factor 6; BrdU, bromodeoxyuridine; CCK-8, cell counting kit-8; CHOP, CCAAT/enhancer-binding protein homologous protein; DAI, disease activity index; DAPI, 4,6-diamidino-2-phenylindole; DSS, dextran sulfate sodium; EdU, 5-ethynyl-2' deoxyuridine; EGFP, enhanced GFP; ER, endoplasmic reticulum; ERS, endoplasmic reticulum stress; FITC, fluorescein isothiocyanate; GPER, G protein-coupled estrogen receptor; GRP78, glucose-regulating peptide 78; IBD, inflammatory bowel disease; IRE1, inositol requiring enzyme 1; ISC, intestinal stem cell; JAM-1, junctional adhesion molecule 1; Lgr5, leucine-rich repeat containing G protein-coupled receptor 5; Lgr5-EGFP, Lgr5-EGFP-IRES-CreERT2; Muc-2, Mucin-2; PAS, periodic acid-Schiff; PERK, double-stranded RNA-dependent protein kinase-like ER kinase; PVDF, polyvinylidene difluoride; TA, transit amplifying; TG, thapsigargin; TJ, tight junction protein; UC, ulcerative colitis; UPR, unfolded protein response. 
Growing evidence links endoplasmic reticulum stress (ERS) and UC (McGuckin et al., 2010; Bogaert et al., 2011). ERS means the accumulation of unfolded/misfolded proteins in the endoplasmic reticulum (ER) lumen, which dissociates glucoseregulating peptide 78 (GRP78) from ER-localized transmembrane protein sensors-inositol requiring enzyme 1 (IRE1), double-stranded RNA-dependent protein kinase-like ER kinase (PERK), and activating transcription factor 6 (ATF6) thereby activating the unfolded protein response (UPR) (McGuckin et al., 2010). Physiologic activation of UPR is an adaptive response for mammalian animals to restore ER homeostasis and maintain epithelial homeostasis (Kaser and Blumberg, 2010). Conversely, prolonged and unmitigated ERS causes mucosal inflammation in UC via multiple mechanisms, such as increased colonic epithelium apoptosis, decreased mucin secretion of goblet cells, and injury of intestinal epithelial stemness and, consequently, impairs mucosal barrier function and mucosal innate immunity (McGuckin et al., 2010; Cao, 2016; Liu et al., 2018). Modulation of ERS and UPR is a potential therapeutic target for UC, and its protective effect upon the epithelial cell is worthwhile (Wu et al., 2010; Bernstein, 2015; Désir-Vignéet al., 2018).

Estrogen plays a crucial role in UC by binding to specific estrogen receptors, the classic nuclear estrogen receptor and membrane estrogen receptor (Harnish et al., 2004; Bábíčková et al., 2015; Jacenik et al., 2019b). The abnormal expression of various estrogen receptors in the colon of patients with UC was not completely the same, suggesting estrogen receptor mediated the effect of estrogen in colitis through a specific signaling pathway (Jacenik et al., 2019b). ER $\beta$ was involved in the architectural maintenance of the colon (Wada-Hiraike et al., 2006), and its activation protected against colitis and colitis-associated neoplasia in mice (Saleiro et al., 2012; Goodman et al., 2017), whereas ER $\alpha$ deletion protected against colitis development (Goodman et al., 2017; Mohammad et al., 2018). The membrane estrogen receptor, G protein-coupled estrogen receptor (GPER), is expressed in the colon ( $\mathrm{Li}$ et al., 2016); its activation mediates rapid intracellular transduction of signals, known as "nongenomic effects" (Prossnitz and Barton, 2014). Very recently, van der Giessen $J$ et al. provided evidence that estrogen improved the barrier function in cultured Caco-2 cells by reducing ERS (van der Giessen et al., 2019). GPER is located not only on the plasma membrane but also the membrane of the ER (Revankar et al., 2005); its activation caused inhibition or promotion of cell apoptosis/death by regulating ERS with a celldependent pattern (Kooptiwut et al., 2014; Han et al., 2019; Lee et al., 2019; Vo et al., 2019). In colorectal cancer cells, GPER took part in cell cycle regulation, proliferation, apoptosis, cell migration, and the regulation of ERS (Jacenik et al., 2019a). GPER activation protected proliferation of jejunum crypt cells from ischemia-reperfusion injury (Chai et al., 2019). Rapid proliferation of crypt cells is essential for intact intestinal epithelial barrier. GPER might be an estrogen receptor involved in the epithelial homeostasis in UC (Włodarczyk et al., 2017; Jacenik et al., 2019b). However, there are no direct studies confirming the role of GPER in colitis.

Fluctuation of estrogen in female animals during the estrus cycle affected GPER expression (Spary et al., 2013; Cheng et al., 2014). Moreover, dysregulation of GPER expression showed gender and age dependence in patients with UC
(Jacenik et al., 2019b). Here we aimed to explore the effect of GPER on acute colitis and its possible mechanism, rather than the gender differences, on GPER function. Therefore, to exclude the possibility that the effect we found might be due to potential changes in estrogen levels, we established the dextran sulfate sodium (DSS)-induced UC model in male mice.

\section{Materials and Methods}

Animals. Male C57BL/6 mice were purchased from the Animal Center of Shandong University. The Lgr5-EGFP-IRES-CreERT2 (Lgr5-EGFP) mice, which were obtained from the Model Animal Research Center of Nanjing University (Nanjing, China), are generated by integrating an enhanced GFP (EGFP)-IRES-CreERT2 cassette at the ATG codon of leucine-rich repeat containing G protein-coupled receptor 5 (Lgr5) (Barker et al., 2007). The Lgr5positive intestinal stem cells of Lgr5-EGFP mice could be specifically labeled with GFP immunofluorescence staining. Each box contained four mice, which were housed under a 12-hour dark-light cycle in a temperature-controlled room. Mice had free access to food and water unless specified otherwise in the text. All animal experiments were approved by Medical Ethics Committee for Experimental Animals, Medical School, Shandong University (Shandong, China) (Ethics Statement number LL-201502061).

Creation of the Acute Colitis Model and Study Protocol. Colitis was induced by administration of $2.5 \%$ DSS (molecular weight, 36,000-50,000; MP Biomedicals, Santa Ana, CA) dissolved in drinking water and given for 7 consecutive days, as described previously (Takagi et al., 2019). During animal model preparation, each mouse was given $8 \mathrm{ml}$ of water daily with or without DSS. According to the requirement of the in vivo experiment, several groups were created: control group (tap water, $0.2 \mathrm{ml}$ of $1 \%$ DMSO, i.p), DSS group (2.5\% DSS in drinking water, $0.2 \mathrm{ml}$ of $1 \%$ DMSO, i.p.), DSS + G-1 (selective GPER agonist) group (2.5\% DSS in drinking water, G-1 $30 \mu \mathrm{g} \mathrm{kg}^{-1}$ in $0.2 \mathrm{ml}$ of $1 \% \mathrm{DMSO}$, i.p.), and DSS + G-1 and G15 (selective GPER blocker) group (2.5\% DSS in drinking water, G-1 $30 \mu \mathrm{g} \mathrm{kg}^{-1}$ in $0.1 \mathrm{ml}$ of $1 \%$ DMSO, and G15 $300 \mu \mathrm{g} \mathrm{kg}^{-1}$ in $0.1 \mathrm{ml}$ of $1 \%$ DMSO, i.p.) (Li et al., 2016; Chai et al., 2019). In addition, control mice were administered G-1 $\left(30 \mu \mathrm{g} \mathrm{kg}^{-1}\right)$ for 7 days to evaluate the effect of G-1 on the physiologic proliferation of crypt cell. All the intraperitoneal injections were performed at 9:00 AM every day. Preliminary experiments showed that intraperitoneal injection of this dose of DMSO had no effect on the colon.

Mice were monitored daily for weight, stool consistency, and fecal bleeding. The disease activity index (DAI) for colitis was evaluated by weight loss, stool consistency, and blood in stools (Takagi et al., 2019). Animals were deeply anesthetized with $4 \%$ to $5 \%$ isoflurane on day 7 , and the entire colon was collected and its length measured. The distal colon was fixed in $4 \%$ paraformaldehyde for 24 hours and embedded in paraffin for histology, or frozen quickly in liquid nitrogen for Western blotting. Finally, mice were euthanized by inhaling excessive isoflurane.

H\&E Staining. Paraffin slices $(4 \mu \mathrm{m})$ of the distal colon were stained with H\&E following the manufacturer's instructions. An epithelium score and infiltration score were calculated according to a scoring system described previously (Hausmann et al., 2007) (Table 1). The histology score was the sum of the epithelium score and infiltration score. A higher score denoted more severe damage. Measurements were made by an observer blinded to the experimental protocol. Three measurements were taken and a mean value obtained.

Immunohistochemical and Immunofluorescence Assays. Paraffin sections $(4 \mu \mathrm{m})$ of the distal colon were dewaxed and rehydrated. Then, they were immersed in $10 \mathrm{mM}$ citrate buffer $(\mathrm{pH}$ 6.0) and heated in a microwave oven for antigen retrieval. Endogenous peroxidase activity was quenched by incubation with $3 \% \mathrm{H}_{2} \mathrm{O}_{2}$ for 
TABLE 1

Scoring system for histologic assessment of colitis (from Hausmann et al., 2007)

\begin{tabular}{lc}
\hline Epithelium & Score \\
\hline Normal morphology & 0 \\
Loss of goblet cells & 1 \\
Loss of goblet cells in large areas & 2 \\
Loss of crypts & 3 \\
Loss of crypts in large areas & 4 \\
Infiltration & \\
No infiltrates & 0 \\
Infiltrate around crypt basis & 1 \\
Infiltrate reaching to lamina muscularis mucosae & 2 \\
Extensive infiltration reaching the lamina muscularis mucosae and thickening of mucosa with severe edema & 3 \\
\hline
\end{tabular}

30 minutes. After rinsing with PBS, the sections were blocked with normal goat serum (ZSGB-BIO, Beijing, China) for 30 minutes.

For immunohistochemical assays, sections were incubated with rabbit polyclonal anti-junctional adhesion molecule 1 (JAM-1) (1:200; ab180821; Abcam, Cambridge, UK), rabbit polyclonal anti-occludin (1: 200; ab168986; Abcam), rabbit polyclonal anti-mucin-2 (1:100; SC515032; Santa Cruz Biotechnology, Santa Cruz, CA), rabbit polyclonal anti-Ki67 (1:300; 12202S; Cell Signaling Technology, Danvers, MA), mouse polyclonal anti-bromodeoxyuridine (BrdU; 1:300; 66241-1-Ig; Proteintech, Chicago), or rabbit polyclonal anti-cleaved caspase-3 (1: 300; 9661S; Cell Signaling Technology) at $4^{\circ} \mathrm{C}$ overnight followed by biotin-labeled secondary antibodies (ZSGB-BIO) for 1 hour at $37^{\circ} \mathrm{C}$. Fifteen minutes after labeling with streptomyces avidin peroxidase (ZSGB-BIO) at room temperature, tissues sections were visualized using a 3,3'-diaminobenzidine tetrahydrochloride kit following the manufacturer's (ZSGB-BIO) protocols. Nuclei were counterstained with hematoxylin. Measurements were undertaken by an observer blinded to the experimental protocol.

To colocate GPER and Lgr5-positive intestinal stem cells (ISCs), double immunofluorescence was carried out on sections from Lgr5EGFP mice. Sections were incubated with rabbit polyclonal antiGPER (1:50; GTX107748; GeneTex, Irvine, CA) and chicken polyclonal anti-GFP (1:500; GFP-1010; Aves Laboratories, Davis, CA). This was followed by incubation with secondary antibodies against rhodamine (Tetramethyl Rhodamin Isothiocyanate )-conjugated goat anti-rabbit IgG (1:50; SA00007-2; Proteintech) and Alexa Fluor 488-labeled goat anti-chicken IgG (1:1000; 1691381; Invitrogen, Carlsbad, CA) in a humid box for 60 minutes in the dark at $37^{\circ} \mathrm{C}$. Nuclei were counterstained with 4,6-diamidino-2-phenylindole (DAPI; Solarbio Life Sciences, Beijing, China).

Periodic Acid-Schiff Staining. Periodic acid-Schiff (PAS) staining was done according to the protocol of a PAS kit (Maixin Biotechnology, Fuzhou, China). Briefly, sections were incubated with $0.5 \%$ PAS solution for 10 minutes. After washing with water, sections were stained with Schiff solution for 10 minutes. Nuclei were counterstained with hematoxylin.

Measurement of Intestinal Permeability In Vivo. Intestinal permeability in vivo was evaluated according to the concentration of fluorescein isothiocyanate (FITC)-dextran (molecular weight, 4000 Da; Sigma-Aldrich, Saint Louis, MO) in blood. After 6 days of DSS administration, mice were fasted overnight. The next morning, mice underwent gavage with FITC-dextran $(400 \mathrm{mg} / \mathrm{kg}$ body weight, dissolved in PBS at $100 \mathrm{mg} / \mathrm{ml}$ ) 4 hours before collecting the blood. After deep inhalation anesthesia with isoflurane, blood samples were drawn from the orbit and centrifuged to collect serum. The FITCdextran concentration in serum was determined by a microplate reader (Molecular Devices, Silicon Valley, CA) at an excitation wavelength of $488 \mathrm{~nm}$ and emission wavelength of $520 \mathrm{~nm}$.

Protein Extraction and Western Blotting. Colon tissue or CCD841 cells cultured in a 6-well plate were placed into the Eppendorf tubes. RIPA lysate (Solarbio Life Sciences, Beijing, China) containing $1 \mathrm{mM}$ PMSF and $1 \mathrm{mM}$ phosphatase inhibitor was added at a dose of
$10 \mu \mathrm{l}$ per microgram of tissue and $100 \mu \mathrm{l}$ per well of cells to lyse the tissue or cell. Tissue and cell proteins were extracted, and the protein concentration was measured using a Bicinchoninic Acid Protein Assay kit (Beyotime Institute of Biotechnology, Beijing, China). About $40 \mu \mathrm{g}$ tissue protein or $20 \mu \mathrm{g}$ cellular protein was used per lane. Protein extracts were separated by sodium dodecyl sulfate-polyacrylamide gel electrophoresis and transferred to polyvinylidene difluoride (PVDF) membranes (Millipore, Bedford, MA). Then, PVDF membranes were rinsed and blocked with 5\% nonfat dry milk for 2 hours at room temperature. PVDF membranes were incubated overnight with specific primary antibodies at $4^{\circ} \mathrm{C}$.

The primary antibodies were mouse polyclonal anti- $\beta$-actin (1: 5000; 66009-1-Ig; Proteintech), rabbit polyclonal anti-cyclin D1 (1: 10000; ab134175; Abcam), rabbit polyclonal anti-cyclin B1 (1:1000, ab181593; Abcam), rabbit polyclonal anti-GRP78 (1:1000; 11587-1-Ap; Proteintech), mouse polyclonal anti-CCAAT/enhancer-binding protein homologous protein (CHOP; 1:1000; 2895S; Cell Signaling Technology), rabbit polyclonal anti-PERK (1:800; AF5304; Affinity Biosciences, Columbus, $\mathrm{OH})$, rabbit polyclonal anti-phosphorylated PERK (1:800; DF7576; Affinity Biosciences), rabbit polyclonal antiIRE1 $\alpha$ (1:1000; 3294; Cell Signaling Technology), rabbit polyclonal anti-phosphorylated IRE1 $\alpha$ (1:1000; ab48187; Abcam), and rabbit polyclonal anti-ATF6 (1:1000; 24169-1; Proteintech).

The next day, after washing with Tris-buffered saline with Tween 20, PVDF membranes were incubated with peroxidase-conjugated goat anti-rabbit IgG (1:5000; SA00004-8; Proteintech) or peroxidaseconjugated goat anti-mouse IgG (1:5000; SA00001-1; Proteintech) for 1 hour at room temperature. Bands were visualized with BeyoECL Plus (Beyotime Institute of Biotechnology) and quantified using a ChemiDoc XRS system and ImageLab (Bio-Rad Laboratories, Hercules, CA) by comparison with the intensity of an internal control.

TUNEL Assay. The TUNEL assay was employed to assess apoptosis using an In-Situ Cell Death Detection kit (Roche, Basel, Switzerland). After dewaxing and rehydration, paraffin-embedded tissue sections were treated with protease $\mathrm{K}$ solution $(20 \mu \mathrm{g} / \mathrm{ml}$ in $1 \times$ PBS) for 30 minutes at $37^{\circ} \mathrm{C}$. Then, $3 \% \mathrm{H}_{2} \mathrm{O}_{2}$ was used to inhibit endogenous peroxidase activity. Next, sections were washed with PBS and incubated with a TUNEL reaction mixture for 60 minutes at $37^{\circ} \mathrm{C}$. Nuclei were counterstained with DAPI. Under a fluorescence microscope (Nikon, Tokyo, Japan), two $200 \times$ fields were captured randomly for each section to obtain the mean percentage of TUNEL-positive cells per field. Measurements were made by an observer blinded to the experimental protocol.

Culture and Treatment of Cells In Vitro. Normal human colonic epithelial cells (CCD841 cells) were purchased from Beijing Beina Chuanglian Biotechnology Institute (Beijing, China) and were used to identify the effect of G-1 on ERS-induced cell injury. Cells were cultured in $4.5 \mathrm{~g} / \mathrm{l}$ glucose-Dulbecco's modified Eagle's medium with $10 \%$ fetal calf serum, $100 \mathrm{U} / \mathrm{ml}$ penicillin, and $100 \mu \mathrm{g} / \mathrm{ml}$ streptomycin in humidified air containing $5 \% \mathrm{CO}_{2}$ at $37^{\circ} \mathrm{C}$.

Preliminary experiments showed that thapsigargin (TG) stimulation for 6 hours upregulated the GRP78 and CHOP expression in CCD841 cells in a dose-dependent manner (data not shown). 
Therefore, we chose the intermediate concentration of TG $(0.5 \mu \mathrm{M})$ to stimulate CCD841 cells in vitro for 6 hours to induce ERS. CCD841 cells were cultured in 6-, 24-, or 96-well plates with a density of $1 \times 10^{5} / \mathrm{ml} ; 1 \mathrm{ml} /$ well was added to the 6 -well plate, $300 \mu \mathrm{l} /$ well was added to the 24 -well plate, and $100 \mu \mathrm{l} /$ well was added to the 96 -well plate. Cells were stimulated with TG in the presence or absence of G-1 $\left(10^{-7}\right.$ M) for various times. The negative control was treated with $0.05 \%$ DMSO only. The final DMSO concentration of each group was $0.05 \%$.

Cell Counting Kit-8 Assay. A Cell Counting Kit-8 (CCK-8) kit (MedChemExpress, Monmouth Junction, NJ) was used to detect the
A

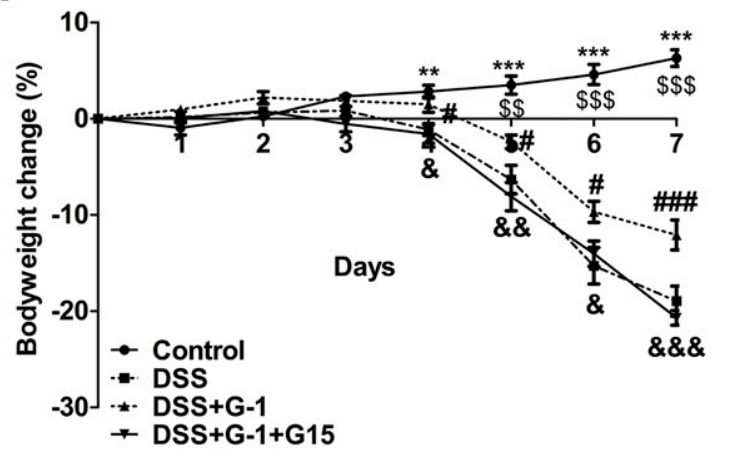

C

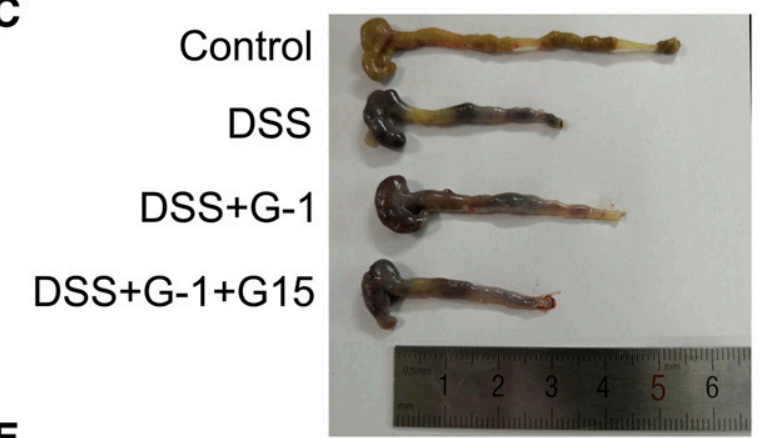

E

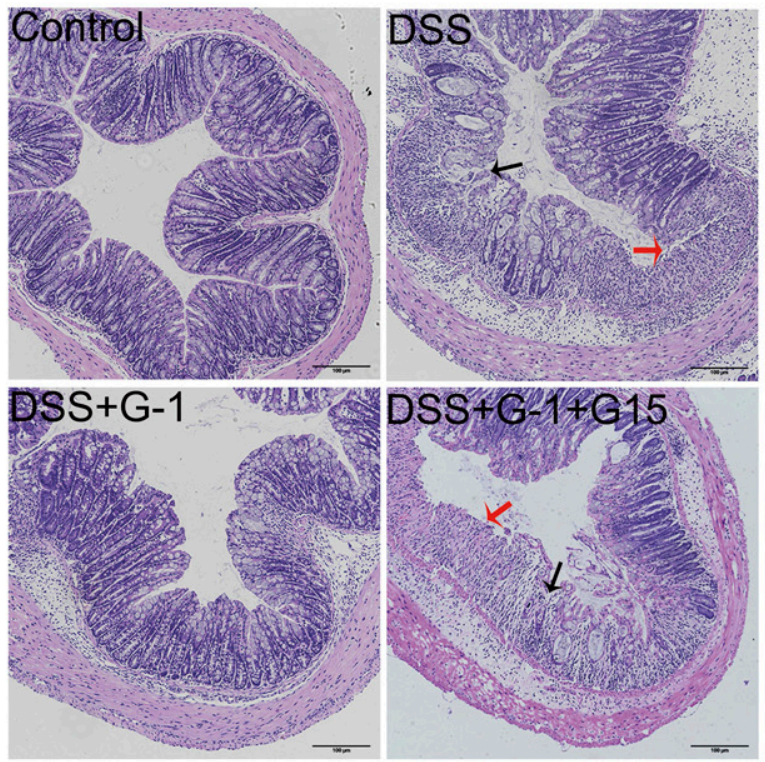

B

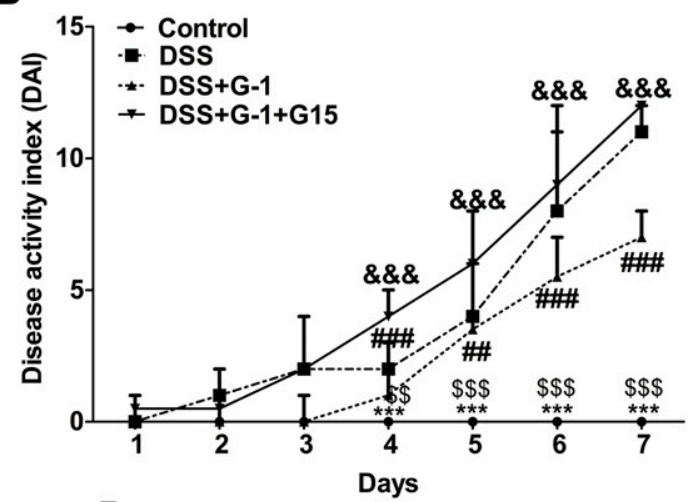

D

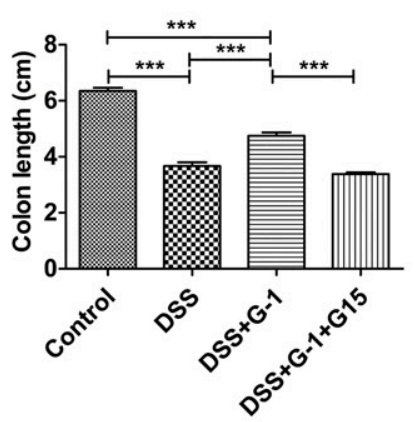

$\mathbf{F}$

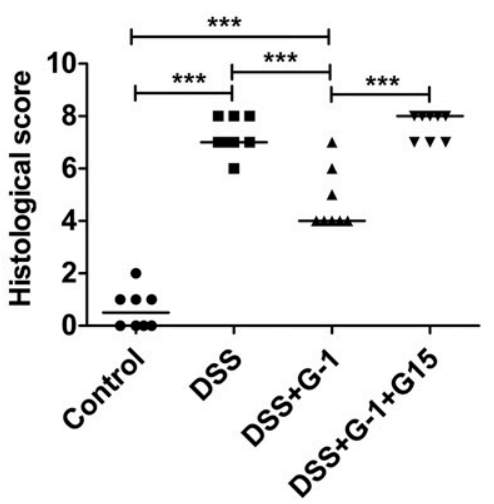

Fig. 1. GPER activation prevented DSS-induced colitis in mice. (A) Body weight change during the disease process within the different experimental groups $(n=8, * * P<0.01$, *** $P<0.001$, vs. DSS; $\$ \$ P<0.01$, $\$ \$ \$ P<0.001$, vs. DSS + G-1 + G15; \#P<0.05, \#\#\#P<0.001, VS.DSS vs. DSS + G-1; \&P< $0.05, \& \& P<0.01, \& \& \& P<0.001$, VS.DSS + G-1 vs. DSS + G-1+G15). (B) DAI change during the disease process within the different experimental

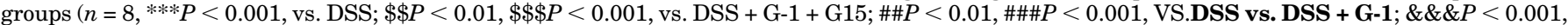
VS.DSS + G-1 vs. DSS + G-1 + G15). (C) Representative photograph of the colon from each group. (D) The statistical chart of colon length within the different experimental groups $(n=6, * * * P<0.001)$. (E) Representative images of colonic histology (H\&E staining, scale bar $=100 \mu \mathrm{m}$ ). The black arrow indicates mucosal ulceration and necrosis. The red arrow indicates destruction, necrosis of crypt, and inflammatory cells infiltrated into the submucosa. (F) The statistical chart for histologic score within the different experimental groups $(n=8, * * * P<0.001)$. The mice were divided into four groups: control, DSS group, DSS + G-1 treatment, and DSS + G-1 and G15 treatment. Data are expressed as means \pm S.E.M. or median. Statistical analyses were performed by one-way ANOVA or the Kruskal-Wallis test followed by the Student-Newman-Keuls method. 
TABLE 2

Body weight of each group before and 7 days after DSS administration Colitis was induced by adding DSS $(2.5 \%)$ in the animals' drinking water for 7 days. Data are expressed as means \pm S.E.M. $(n=8)$.

\begin{tabular}{lcc}
\hline \multirow{2}{*}{ Group } & \multicolumn{2}{c}{ Body weight $(\mathrm{g})$} \\
\cline { 2 - 3 } & 0 day & 7 th day \\
\hline Control & $21.99 \pm 0.54$ & $23.36 \pm 0.48$ \\
DSS & $21.45 \pm 0.26$ & $17.36 \pm 0.28^{* * * *}$ \\
DSS + G-1 & $21.71 \pm 0.29$ & $19.11 \pm 0.52^{\#}$ \\
DSS + G-1 + G15 & $22.04 \pm 0.10$ & $17.48 \pm 0.21^{\& \&}$ \\
\hline
\end{tabular}

${ }^{* * * *} P<0.001$, vs. control.
${ }^{\#} P<0.05$, vs. DSS.

${ }^{\& \&} P<0.01$, vs. DSS + G-1.

effect of G-1 treatment on the number of viable CCD841 cells after TG stimulation. CCD841 cells were cultured in a 96-well plate and grouped according to the methods mentioned above. Ten microliters CCK-8 reagent was added to each well at the indicated time and further cultured for 2 hours at $37^{\circ} \mathrm{C}$. Zero, $6,24,48$, and 72 hours after G-1 treatment, the optical density value of each well was measured at $450 \mathrm{~nm}$ with a microplate reader according to the kit instructions to evaluate the cell survival. The higher the optical density, the more living cells.

Labeling with 5-Ethynyl-2'-Deoxyuridine in Cultured CCD841 Cells. To assess the effect of GPER activation upon proliferation of CCD841 cells under ERS, the proliferation of CCD841 cells cultured in 24-well plates was detected by an 5-ethynyl-2'deoxyuridine (EdU) Cell Proliferation Assay kit (Ruibo Biotech, Guangzhou, China) 48 hours after G-1 administration. Briefly, $50 \mu \mathrm{M}$ EdU was added to the culture medium 3 hours before testing. Cells were fixed and permeabilized, and EdU staining was done according to the manufacturer's protocols. To count the total number of cells, cells were incubated with $1 \mathrm{mg} / \mathrm{ml}$ Hoechst 33342 (Ruibo Biotech) for 30 minutes at room temperature. For each sample, three $200 \times$ fields were selected randomly under a fluorescence microscope (Nikon), the proportion of EdU-positive cells to Hoechst-positive ones calculated, and the mean value taken.

Drugs and Chemicals. G-1 was purchased from ApexBio (Houston, TX). G15 was obtained from Cayman Chemicals (Ann Arbor, MI). DSS was purchased from MP Biomedicals (Santa Ana, CA). TG was obtained from Sigma-Aldrich. Isoflurane was obtained from RWD Life Science (Shenzhen, China).

Statistical Analyses. Except for data that did not conform to a normal distribution, data were expressed as means \pm S.E.M. Unpaired $t$ tests were used to compare differences between two groups. One-way analysis of variance followed by the StudentNewman-Keuls method was employed for multiple-group comparisons. The Kruskal-Wallis test followed by the Student-NewmanKeuls test was used for data with a nonnormal distribution. $P<0.05$ was considered significant.

\section{Results}

Activation of GPER Reduced the Severity of DSS-Induced Acute Colitis. Mice receiving DSS exhibited symptoms similar to colitis in humans: diarrhea, bloody stools, and sustained weight loss. Administration of the selective GPER agonist G-1 with DSS together alleviated all of these symptoms, improved the DAI significantly, and inhibited colon shortening (Fig. 1, A-D; Table 2). Mucosal erosions, ulcerations, and infiltration with polymorphonuclear cells, as well as distortion, destruction, and even disappearance of crypts were found in mice suffering from colitis, all of which were relieved by G-1 treatment, thereby resulting in a decline in histology scores (Fig. 1, E and F). The protective effect of G-1 on DSS-induced colitis was blocked by selective GPER antagonist G15 (Fig. 1).

Location of GPER in the Colonic Epithelium and Change of GPER Expression in DSS-Induced Colitis. To identify the GPER expression in the colonic epithelium, we used the Lgr5-EGFP mice to costain the Lgr5 ${ }^{+}$stem cell and GPER. GPER was expressed in the Lgr5 ${ }^{+}$stem cell and transit-amplifying (TA) cells in colonic crypt (Fig. 2A). GPER expression significantly increased in acute colitis model, whereas G-1 treatment did not affect its expression in colitis (Fig. 2B).

GPER Activation Protected Colonic Mucosal Barrier in DSS-Induced Colitis. Since disruption of mucosal barrier is the key pathologic change of colitis, next we tested the effect of GPER activation on the mucosal barrier in the colitis model. After DSS stimulation, expression of JAM-1 and occludin (key components of tight junction proteins) decreased obviously compared with that in the control group (Fig. 3, A and B). The abnormal expression of JAM- 1 and occludin in mice suffering from colitis was ameliorated by G-1 administration (Fig. 3, A and B). Mucin-2 (Muc-2) secreted by goblet

A
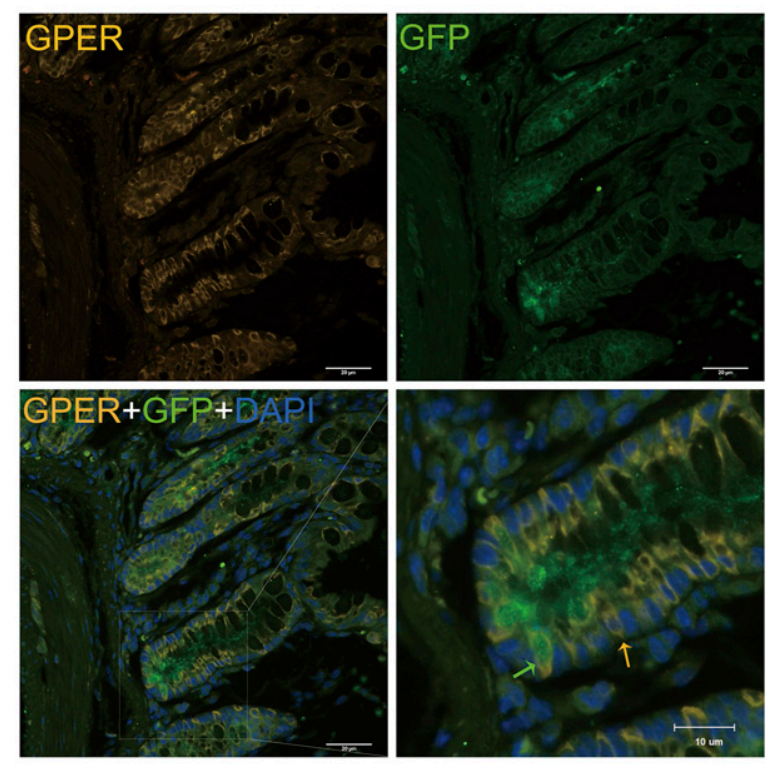

B
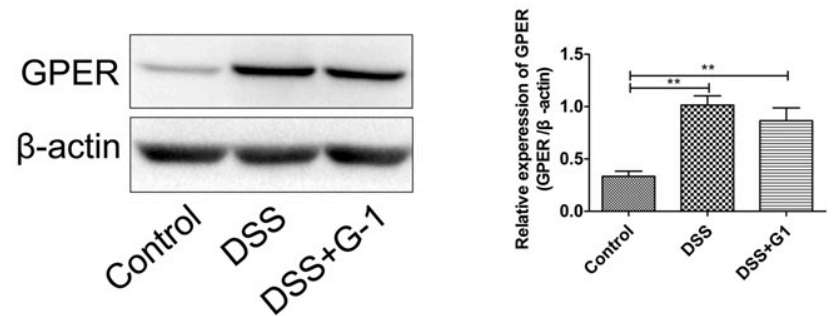

Fig. 2. Expression of GPER in colon epithelium and change of GPER expression in colitis. (A) Immunofluorescence detection of GPER in crypt from the Lgr5-EGFP mouse. The Lgr5 ${ }^{+}$intestinal stem cells were marked by GFP. DAPI was used as a nuclear stain. The green arrow indicates the GPER-positive $\mathrm{Lgr}^{+}$stem cell, and the yellow arrow indicates other GPER-positive cells in crypt (scale bar: lower right quarter trace was 10 $\mu \mathrm{m}$; others were $20 \mu \mathrm{m}$ ). (B) GPER expression in acute colitis model with or without G-1 treatment $(n=4, * * P<0.01)$. Data are expressed as means \pm S.E.M. Statistical analyses were performed by one-way ANOVA followed by the Student-Newman-Keuls method. 
cells is the major component of the mucus barrier. PAS staining and Muc-2 staining revealed decreased goblet cells and reduced mucus layer in the colitis model. G-1 treatment significantly improved mucous layer in colitis mice and upregulated the number of Muc-2-positive goblet cells per crypt in mice suffering from colitis (Fig. 3, C-E). Accordingly, the increased colonic mucosal permeability in mice afflicted with colitis was restored by G-1 treatment (Fig. 3F).

GPER Activation Depressed ERS and UPR in Acute Colitis. The intestinal epithelial cells, particularly secretory cells, are susceptible to ERS, and enlarged ERS is involved in mucosal barrier disruption in UC (Kaser et al., 2010; McGuckin et al., 2010). Compared with that in the control group, we found upregulation of GRP78 and CHOP expression in the colonic tissue of the UC model, as well as the activity of PERK, IRE1 $\alpha$, and expression of ATF6, suggesting the enlarged ERS and UPR activation induced by colitis. Both the upregulation of GRP78 and CHOP expression and the activation of all three arms of UPR in mice afflicted with colitis were inhibited by G-1 treatment (Fig. 4).

GPER Activation Reduced Apoptosis of Crypt Cells and Protected the Proliferation of Crypt Cells in DSS-Induced Colitis. Histologic staining showed that the apoptosis of colonic epithelial cells in the colitis model was significantly increased, and the apoptotic cells were mainly distributed in the lower part of the crypt (Fig. 5, A and C). G-1 treatment alleviated the increase in the number of cleaved caspase-3-positive cells and TUNEL-positive cells in the
A

JAM-1
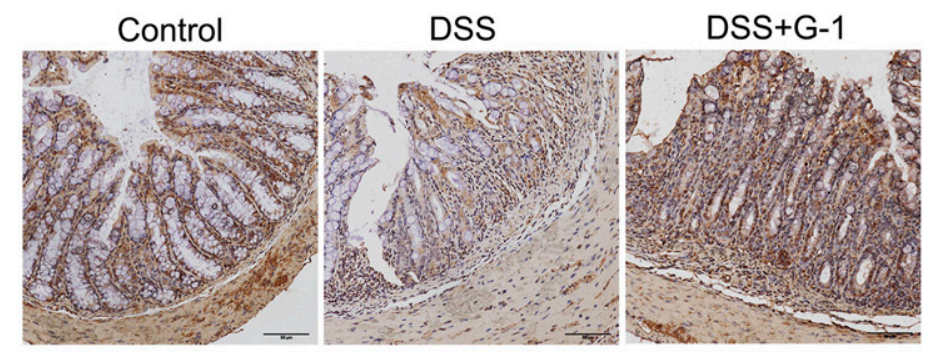

B
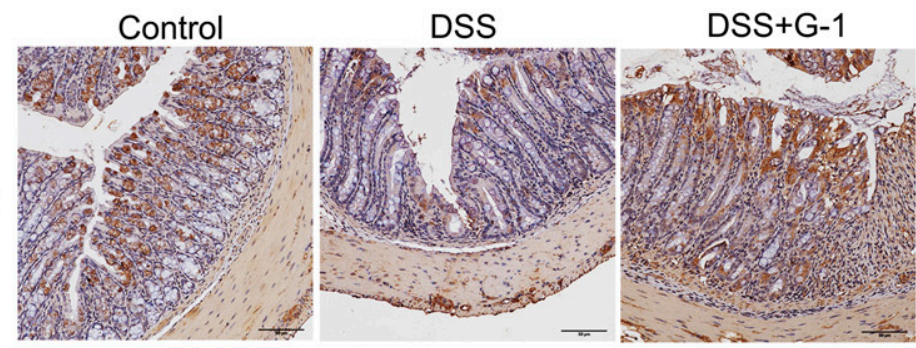

C
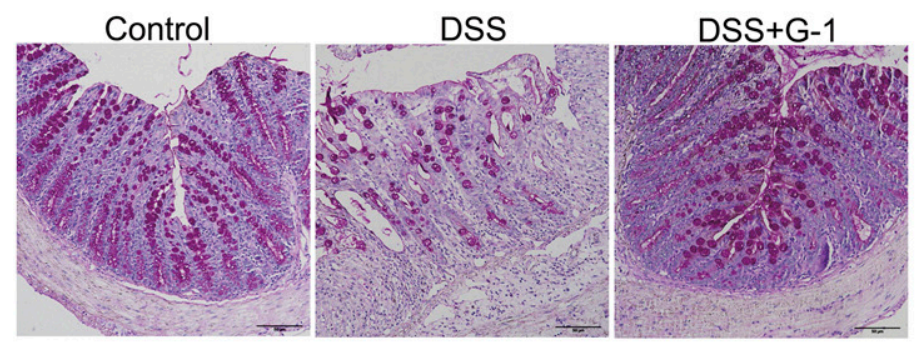

D
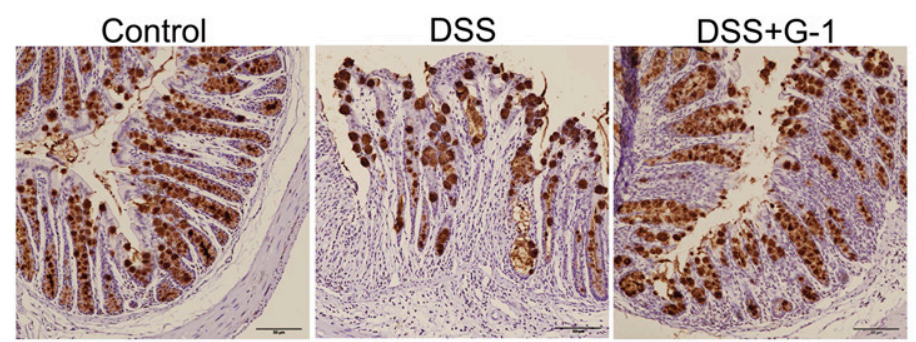

E

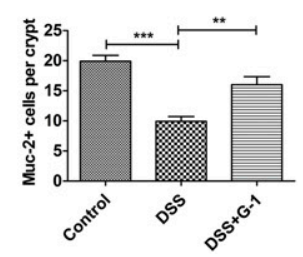

$\mathbf{F}_{\overline{\mathrm{s}}}$

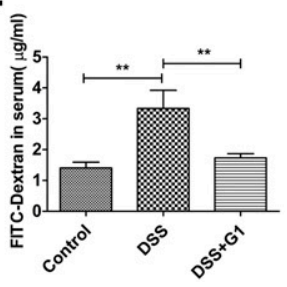

Fig. 3. GPER activation protected colonic mucosal barrier in DSS-induced colitis. (A) Immunohistochemical staining for JAM-1 in distal colon for each group (scale bars: $50 \mu \mathrm{m}$ ). (B) Immunohistochemical staining for occludin in distal colon for each group (scale bars: $50 \mu \mathrm{m}$ ). (C) Representative photographs of colon sections stained for mucous layers with PAS staining for each group (scale bars: $50 \mu \mathrm{m}$ ). (D) Representative images for immunohistochemical staining of Muc-2 in distal colon for each group (scale bars: $50 \mu \mathrm{m}$ ). (E) Statistical chart of (D) $(n=6$ mice per group, five crypts were randomly calculated in each section in a blinded fashion, and the average value was obtained; ${ }^{*} P<0.01$, *** $P<0.001$ ). (F) Effect of G-1 treatment on colonic mucosal permeability in colitis mice. The permeability was evaluated by FITC-dextran concentration in serum. The mice received an oral gavage of FITC-dextran $(400 \mathrm{mg} / \mathrm{kg}) 4$ hours before collecting blood, and serum FITC-dextran concentrations were determined to reflect the colonic mucosal permeability $\left(n=8,{ }^{* *} P<0.01\right)$. The mice were divided into three groups: control, DSS treatment group, and DSS + G-1 treatment. Data are expressed as means \pm S.E.M. Statistical analyses were performed using one-way ANOVA followed by the Student-Newman-Keuls method. 
A
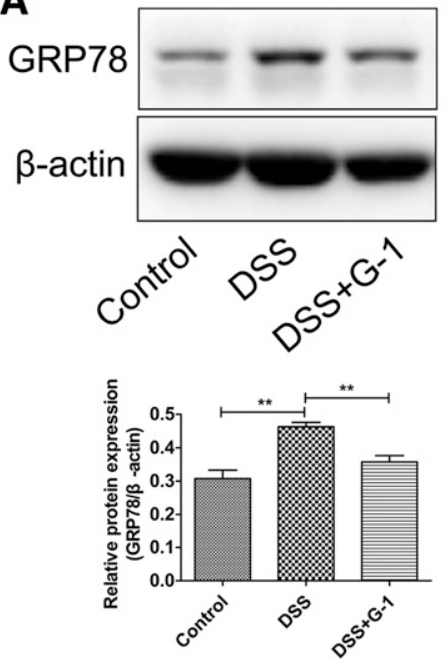

C
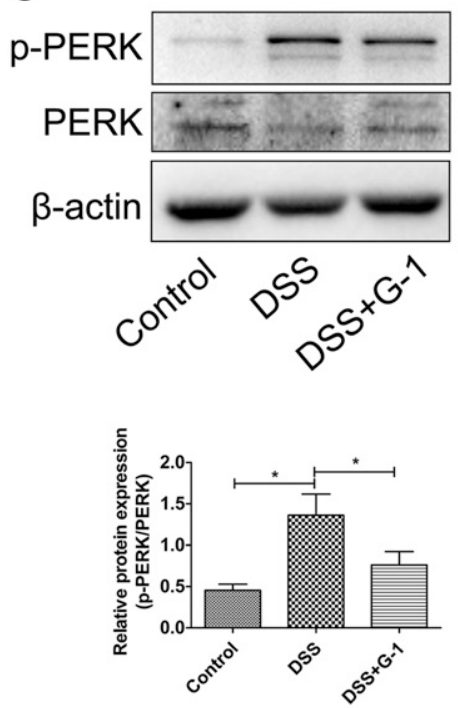

E
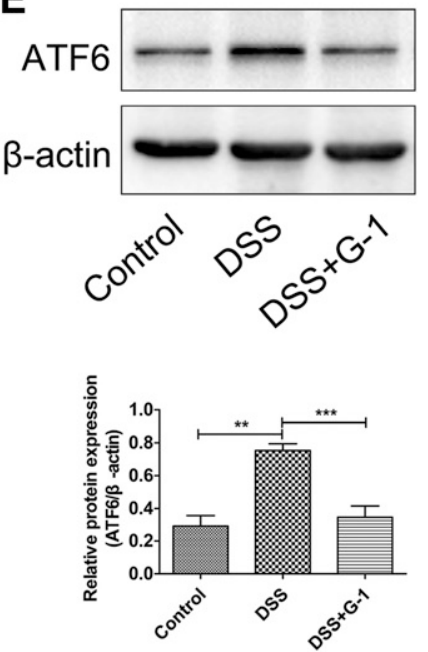

B
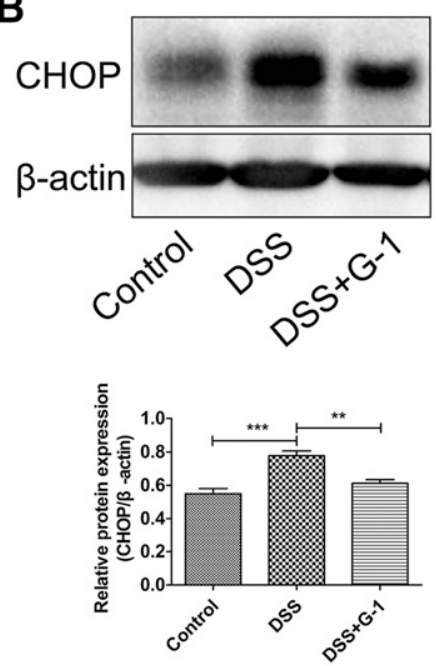

D
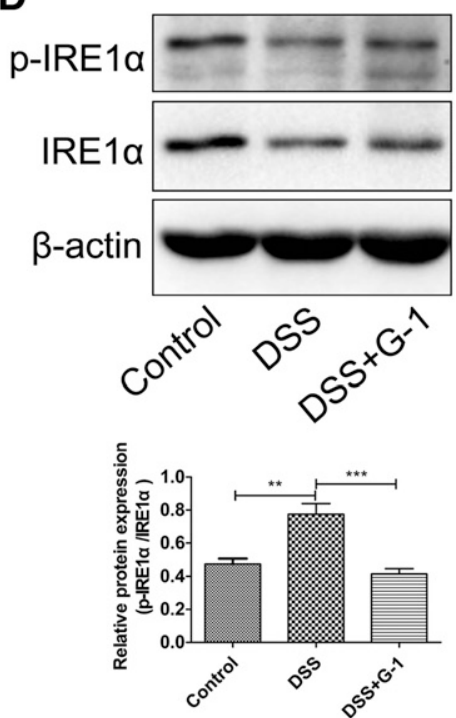

Fig. 4. GPER activation inhibited the ERS and UPR in DSSinduced colitis. (A) Effect of G-1 treatment on GRP78 expression in colitis (the figure above was the original one, and the figure below was the statistical one; $n=4, * * P<$ 0.01). (B) Effect of G-1 treatment on CHOP expression in colitis (the figure above was the original one, and the figure below was the statistical one; $n=4$, *** $P<0.001, * * P<$ 0.01). (C) Effect of G-1 treatment on PERK activity in colitis (the figure above was the original one, and the figure below was the statistical one; $n=4, * P<0.05$ ). (D) Effect of G-1 treatment on IRE $1 \alpha$ activity in colitis (the figure above was the original one, and the figure below was the statistical one; $n=4, * * P<0.01, * * * P<0.001$ ). (E) Effect of G-1 treatment on ATF6 expression in colitis (the figure above was the original one, and the figure below was the statistical one; $n=$ $4, * * P<0.01, * * * P<0.001)$. The mice were divided into three groups: control, DSS treatment group, and DSS + G-1 treatment. Data are expressed as means \pm S.E.M. Statistical analyses were performed using one-way ANOVA followed by the Student-Newman-Keuls method. 
crypts of mice suffering from colitis (Fig. 5, A-D). Compared with the control group, the number of proliferating cells in crypts (measured by Ki67 staining) and the number of S-phase cells in crypts (measured by BrdU staining) decreased significantly in the colitis group (Fig. 6, A and B). G-1 administration reversed the reduction in the number of Ki67-positive cells and S-phase cells in mice suffering from colitis (Fig. 6, A and B). In accordance with immunohistochemical staining results, G-1 reversed downregulation of cyclin D1 and cyclin $\mathrm{B} 1$ expression in mice suffering from colitis (Fig. 6, C-E). The number of Ki67-positive cells in the crypt showed an increasing trend 7 days after G-1 administration in control mice, but no statistical significance was found (Fig. 6F).

GPER Activation Fought Against the ERS-Induced Cell Injury In Vitro. To further elucidate the protective effect of GPER activation on cells by inhibiting ERS, we established a TG-induced ERS model using CCD841 cells. G-1 administration reduced TG-induced upregulation of GRP78 and CHOP expression significantly (Fig. 7). In the ERS model, compared with the control group, the number of living cells detected by the CCK-8 method was significantly decreased at 24,48 , and 72 hours, whereas G-1 treatment improved the decreasing of living cells induced by ERS, which was most significant at 48 hours after G-1 treatment (Fig. 8C). Accordingly, analyses of EdU incorporation showed that the percentage of EdU-positive cells decreased from 56.25\% \pm $3.092 \%$ to $26.25 \% \pm 2.287 \%$ in the ERS group compared with that in the control group (Fig. 8, A and B). Forty-eight hours after G-1 treatment in the ERS group, the percentage of EdUpositive cells increased to $44.5 \% \pm 1.658 \%$ (Fig. $8, \mathrm{~A}$ and B).
Consistently, downregulation of expression of cyclin D1 induced by ERS was inhibited 12 hours after G-1 treatment in vitro (Fig. 8, D and $\mathrm{E}$ ).

\section{Discussion}

$\mathrm{UC}$ is a common and recurrent disease, and its incidence is increasing worldwide (Ng et al., 2018). We demonstrated that selective GPER agonist G-1 inhibited weight loss, colon shortening, and histologic injury in mice with acute colitis and improved the DAI significantly. All these effects were abrogated in the presence of a selective GPER antagonist. Further studies showed that GPER activation depressed the enlarged ERS and UPR during acute colitis, thereby inhibiting the mucosal barrier disruption by protecting colonic crypt cells.

Estrogen modulates gut inflammation by acting on a variety of estrogen receptors, but reports about its effect on colitis seemed inconsistent. Males were more prone to colitis (Bernstein et al., 2006; Bábíćková et al., 2015), and hormonal replacement therapy had a protective effect for disease activity in postmenopausal women with IBD (Kane and Reddy, 2008). In contrary, there was a report that estrogen supplement increased the risk of UC in postmenopausal women (Khalili et al., 2012). The diversity of estrogen receptor types is related to the complexity of estrogen action, and different estrogen receptor activation might mediate different or even completely opposite effects (Harnish et al., 2004; Kumral et al., 2014; Jacenik et al., 2019b). Compared with estrogen, G-1 selectively activates GPER-dependent
A
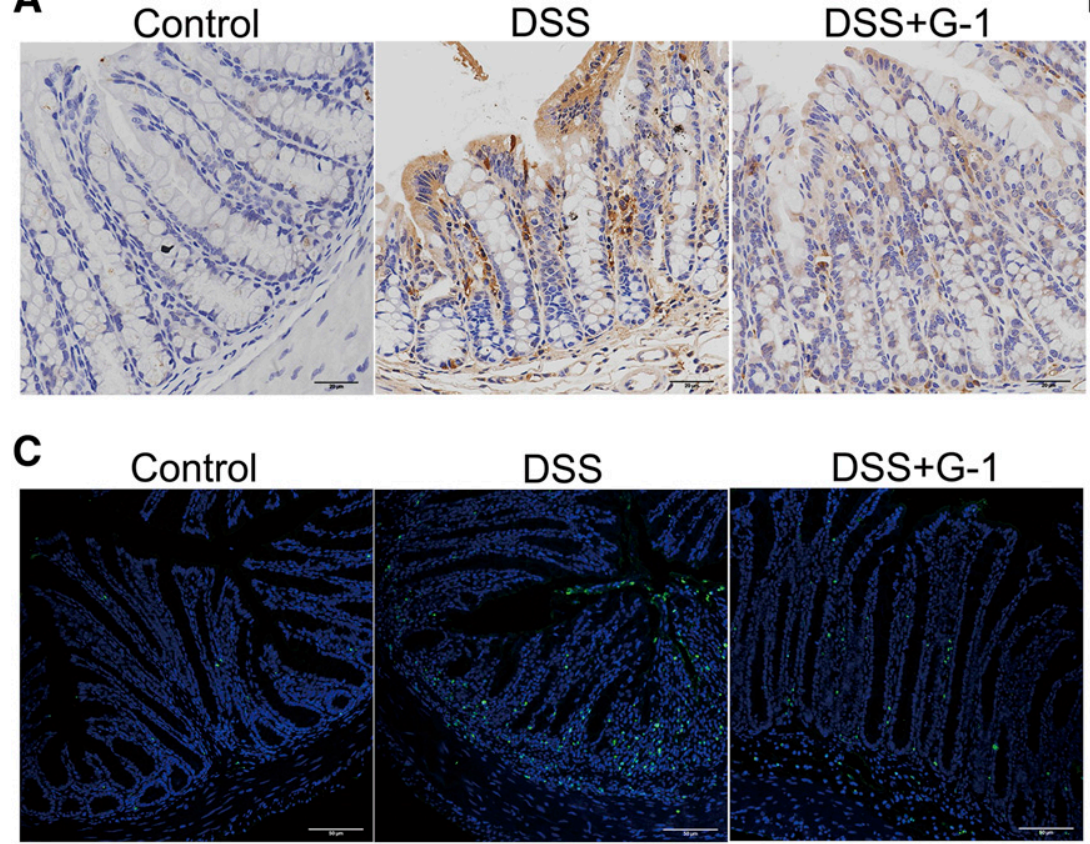

B

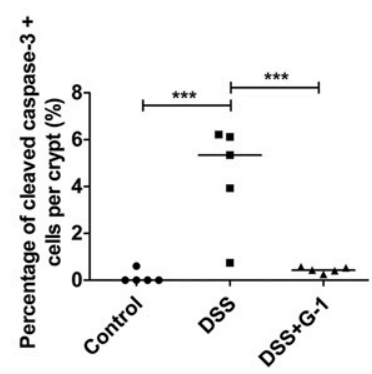

D

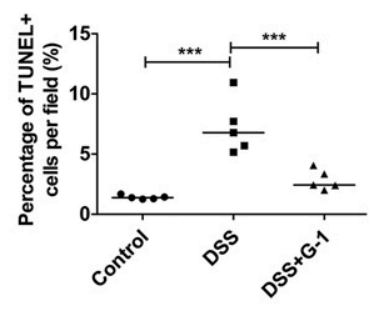

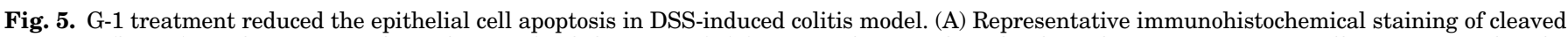

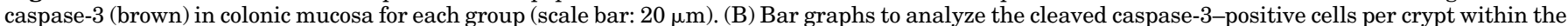

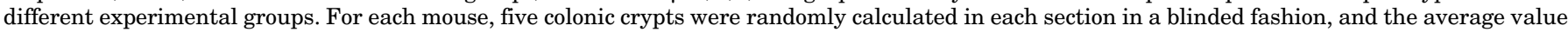

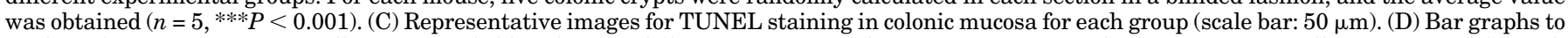

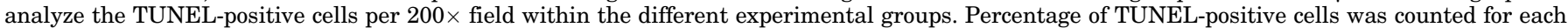

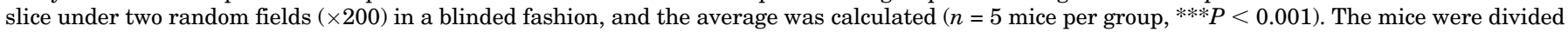

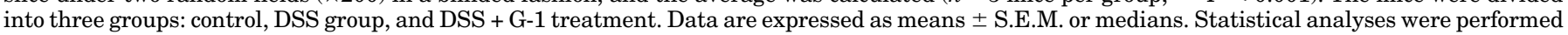
using one-way ANOVA or the Kruskal-Wallis test followed by the Student-Newman-Keuls method. 


\section{A}
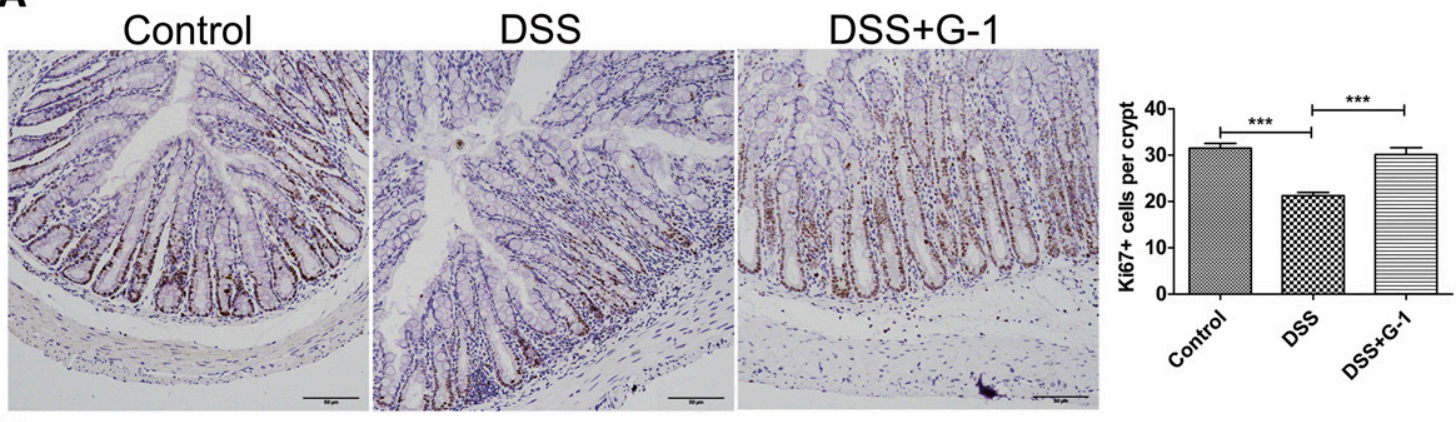

\section{B}

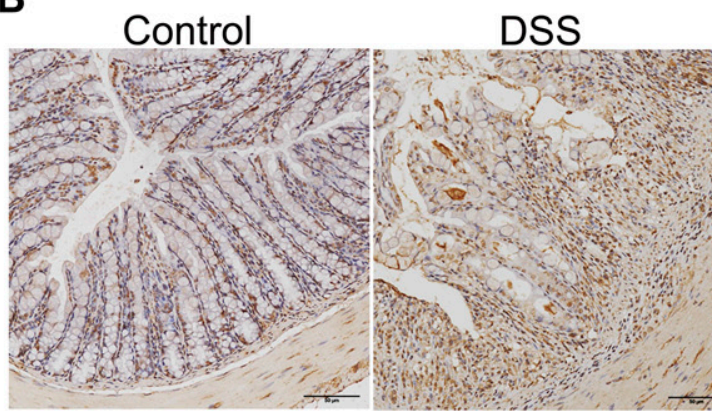

C

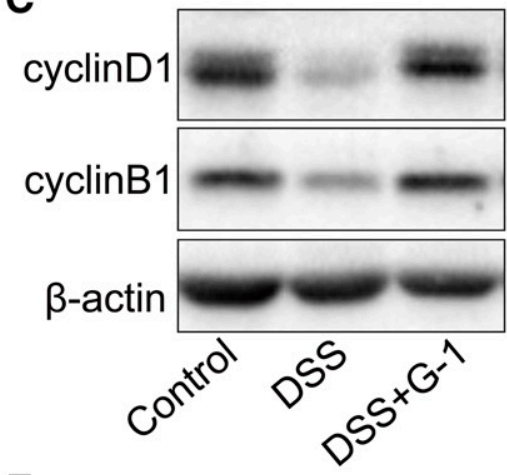

$\mathbf{E}$

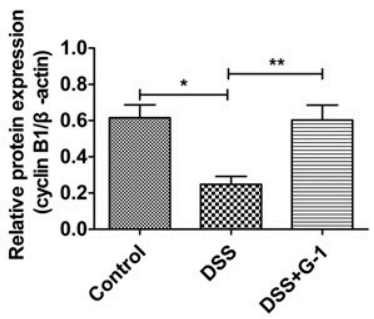

DSS+G-1
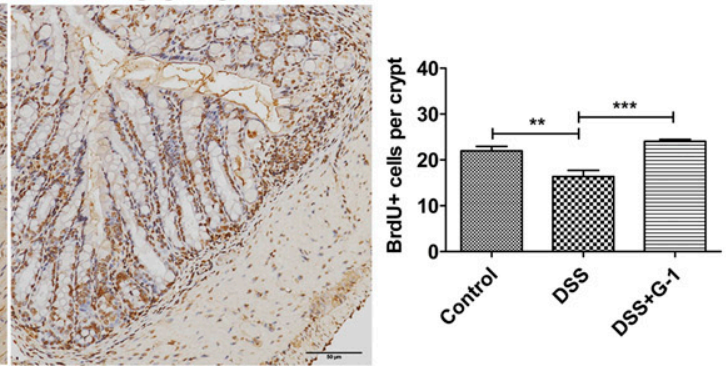

Fig. 6. G-1 treatment protected the crypt cell proliferation in DSS-induced colitis. (A) Representative figures for Ki67 staining (scale bar: $50 \mu \mathrm{m}$ ) and statistical chart of Ki67-positive cells per crypt. Five colonic crypts were randomly calculated in each section in a blinded fashion, and the average value was obtained $(n=6, * * * P<0.001)$. (B) Representative figures for BrdU incorporation in crypt in colon (scale bar: $50 \mu \mathrm{m})$ and statistical chart of BrdUpositive cells per crypt. Five colonic crypts were randomly calculated in each section in a blinded fashion, and the average value was obtained $(n=6$, ** $P<0.01$, ${ }^{* *} P<0.001$ ). (C) Representative Western blot photographs for cyclin D1 and cyclin B1. (D) Densitometry analysis of cyclin D1 in colonic tissue within the different experimental groups $(n=4, * * P<0.01, * * * P<0.001)$. (E) Densitometry analysis of cyclin B1 in colonic tissue within the different experimental groups $(n=4, * P<0.05, * * P<0.01)$. (F) Statistical chart of Ki67-positive cells per crypt after G-1 treatment in control mice. Five colonic crypts were randomly calculated in each section in a blinded fashion, and the average value was obtained. In addition to (F), mice were divided into three groups: control group, DSS group, and DSS group. In (F) mice were divided into control and control + G-1 group. Data are expressed as means \pm S.E.M. Statistical analyses were performed using one-way ANOVA followed by the Student-Newman-Keuls method or unpaired $t$ test.

downstream signaling pathway, making its effects more precise and easily controlled. In addition, GPER activation lacks the feminizing effects associated with agonists of the nuclear estrogen receptor activation. GPER may be a better therapeutic target for UC. Here, with a DSS-induced acute colitis model, we found that G-1 treatment prevented the development of clinical symptoms in colitis, such as weight loss, shortened colon length, hemorrhagic diarrhea, and morphologic changes. Its effect was blocked by selective GPER antagonist G15. In line with previous report from 
A

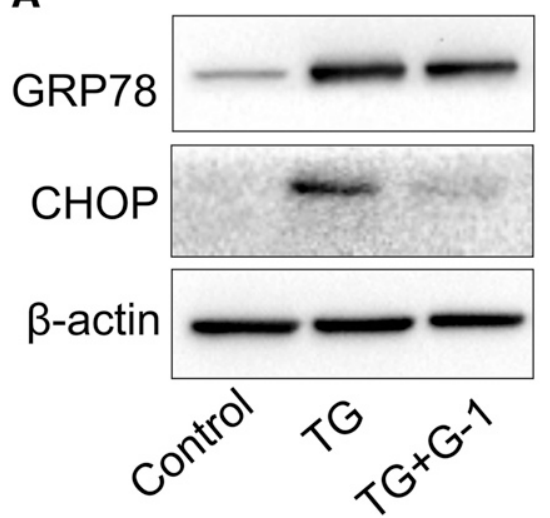

B

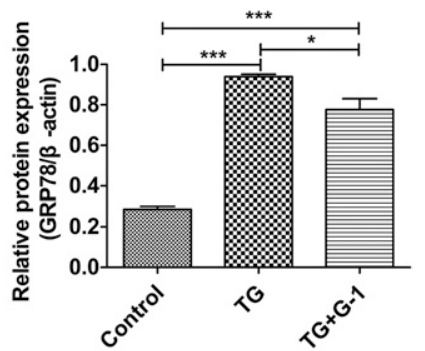

C

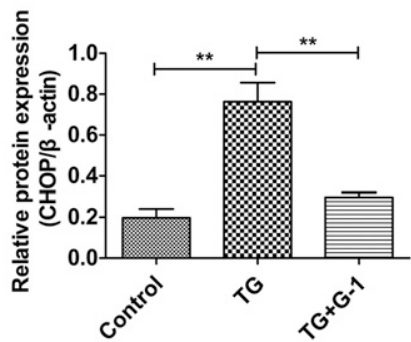

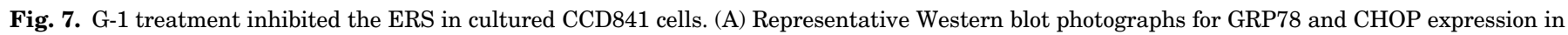

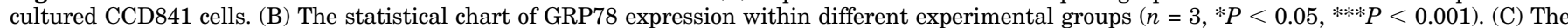

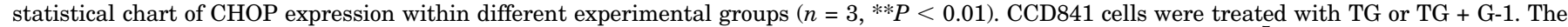

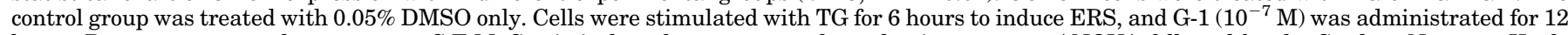

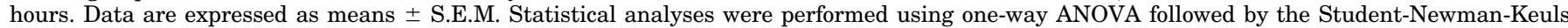
method.

patients with UC (Jacenik et al., 2019b), we found that GPER expression increased significantly in the acute colitis model. Unlike the report in the mouse model of Crohn's disease (Jacenik et al., 2019c), G-1 treatment did not inhibit the upregulation of GPER expression in colitis. The difference might be related to the mice, pathologic model, and the method of drug administration. It seemed that the upregulation of GPER expression might be an adaptive response of UC and that the protective effect of G-1 on colitis was achieved by activating the downstream signaling pathway of GPER.

Colitis is characterized by contiguous inflammation of the colonic lamina propria, followed by injury and disruption of the mucosal barrier, including physical barrier of intestinal epithelial cells joined by tight junction proteins (TJs) and the mucus barrier (Turner, 2009). Consistent with a previous report (Ma et al., 2018), the expression of JAM-1 and occluding (the main type of TJs) was diminished considerably in mice suffering from colitis, whereas G-1 protected the TJs' expression in the colitis. Patients with UC displayed decreased numbers of goblet cells and impaired formation of mucin granules (McGuckin et al., 2011). G-1 treatment improved the disruption of mucus layers and inhibited the decreasing of Muc-2-positive cells significantly in the colitis model, suggesting its beneficial effect on goblet cells. Consistent with these morphologic changes, G-1 treatment in vivo inhibited the increase of colonic permeability in the colitis model significantly. The mucosal barrier dysfunction facilitates invasion by intestinal microorganisms, resulting in a rapid and profound inflammatory immune response, colonic mucosal inflammation, and even life-threatening bacterial translocation (Fink and Delude, 2005; Turner, 2009). GPER activation protected the jejunal mucosal permeability in ischemia reperfusion injury (Chai et al., 2019) and blood-brain barrier permeability in cerebral ischemia ( $\mathrm{Lu}$ et al., 2016). It is reasonable to conclude that the beneficial effects of GPER on colitis were related to protecting the mucosal barrier.

Intestinal epithelial cells, especially the high secretory cells, are susceptible to ERS because they require a fine monitoring and management of the ER to avoid the accumulation of unfolded/misfolded proteins (Cao, 2016). The increased ERS localized mainly in the epithelial lining of the gut rather than in the recruited inflammatory cells in tissue samples from patients with IBD (Bogaert et al., 2011), which was associated with increased intestinal permeability (Wu et al., 2010), and alleviating ERS helps to prevent epithelial barrier dysfunction (Désir-Vigné et al., 2018). The upregulation of ERS marker GRP78 and CHOP expression, as well as the activity of PERK, IRE $1 \alpha$, and ATF6 expression, was inhibited by G-1 treatment, indicating the inhibitory effect of GPER on ERS and UPR during acute colitis. Prolonged or severe ERS induces the apoptosis of intestinal epithelial cells by activation of the proapoptotic UPR and the transcription factor CHOP (Oyadomari and Mori, 2004; Wu et al., 2010; Tabas and Ron, 2011). G-1 administration reduced the number of caspase-3-positive cells and the number of TUNEL-positive cells in the crypt in DSS-induced colitis. Similar to previous reports (Iwamoto et al., 1996; Dirisina et al., 2011), the increased apoptosis of colonic epithelial cells in colitis mice occurred mainly in the lower crypt of the colon, occupied by Lgr5 ${ }^{+}$ISCs and TA cells. The Lgr $5^{+}$intestinal stem cells divide asymmetrically to produce TA cells, which divide continuously and differentiate into mature intestinal epithelial cells (Barker, 2014). Rapid proliferation of Lgr5 ${ }^{+}$ISCs and TA cells is the key for regeneration and repair of intestinal mucosal barrier. The apoptosis of crypt cells may inhibit mucosal healing by affecting the proliferation ability of crypt cells (Kraft et al., 2017; Désir-Vigné et al., 2018; Liu et al., 2018). We found that G-1 administration significantly inhibited the reduction of Ki67- and BrdU-positive cells in the crypt of the DSS group. Cyclin D1 is a regulator of the G1 to S transition in cell cycle (Baldin et al., 1993), whereas cyclin B1 leads to transition from G2 to M phases (Johansson and Persson, 2008). The downregulation of cyclin D1 and cyclin B expression in DSS treatment group was prevented by G-1, which helped mucosal regeneration in DSS-induced colitis (Deng et al., 2018). Increased apoptosis or impaired proliferation of crypt cells is closely related to the destruction of intestinal mucosal barrier (Araki et al., 2012; Su et al., 2013). Immunofluorescence staining showed GPER expressed in colonic 
A

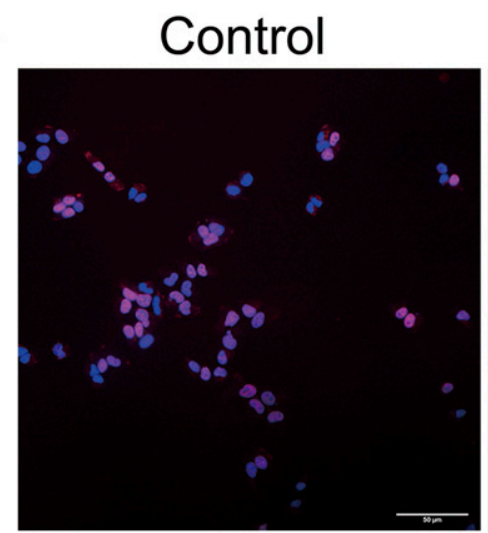

TG

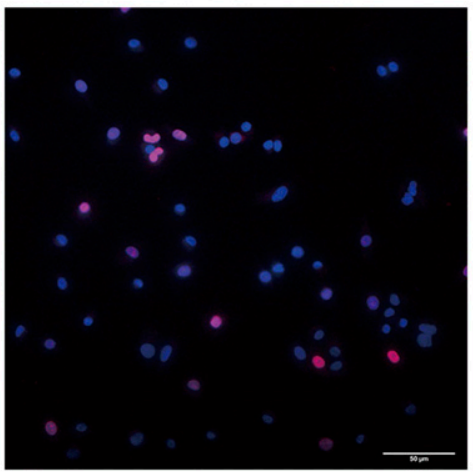

$\mathrm{TG}+\mathrm{G}-1$

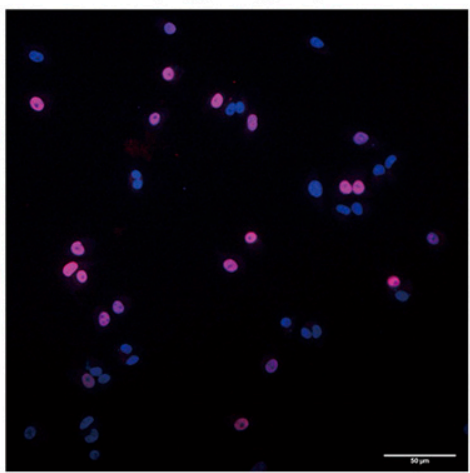

B

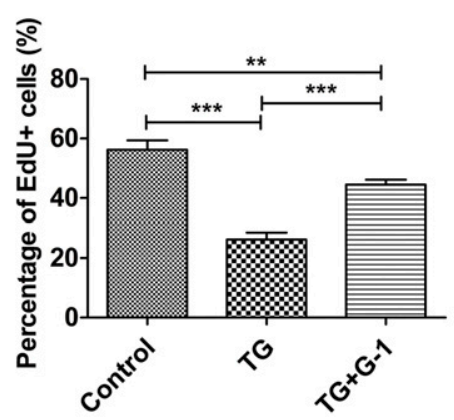

D
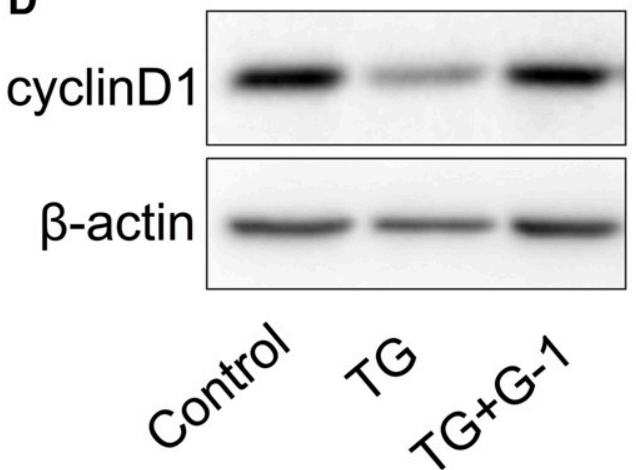

C

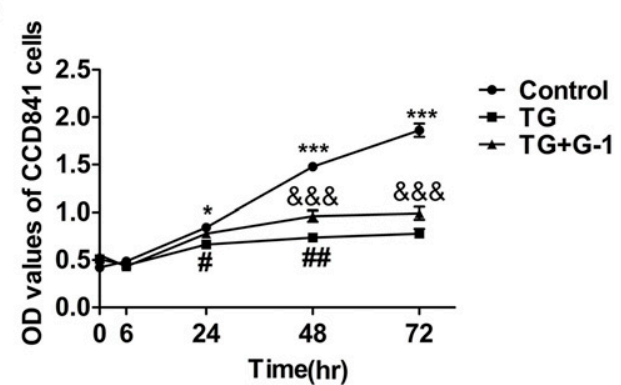

E

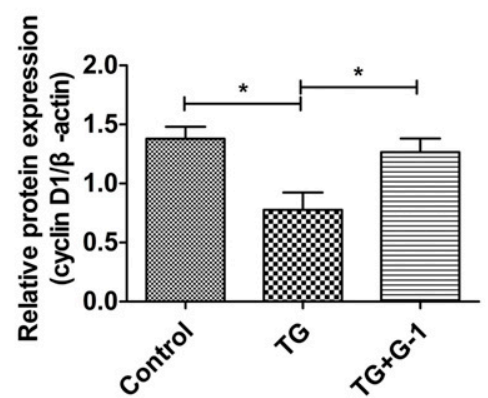

Fig. 8. GPER activation inhibited the cell injury induced by ERS in vitro. (A) Fluorescence image of in vitro cultured CCD841 cells treated with EdU for 3 hours to show EdU-positive cells (red) in different groups (scale bar: $50 \mu \mathrm{m}$ ). The EdU incorporation test was performed 48 hours after G-1 treatment. (B) Quantitative results of EdU incorporation test. For each sample, three $200 \times$ fields were randomly selected under fluorescence microscope, the proportions of EdU staining-positive cells to Hoechst staining-positive ones was calculated by a blind observer, and the mean value was taken $(n=4$, ${ }_{* *} P<0.01$, ***P $P 0.001$ ). (C) Effect of G-1 on the number viable cells proliferation under ERS. The cell was evaluated by CCK- 8 test $(n=3$, $* P<0.05$,

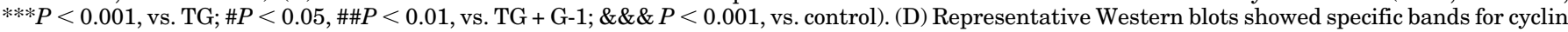
D1. The cells were collected for Western blot 12 hours after G-1 treatment. (E) The statistical chart for (D) within different experimental groups $(n=3$, $* P<0.05)$. CCD841 cells were treated with TG or TG + G-1. The control group was treated with $0.05 \%$ DMSO only. Cells were stimulated with TG for 6 hours to induce ERS, and the treatment time of G-1 $\left(10^{-7} \mathrm{M}\right)$ was selected according to the experimental needs. Data are expressed as means \pm SEM. Statistical analyses were performed using one-way ANOVA followed by the Student-Newman-Keuls method.

crypt, including the Lgr5 ${ }^{+}$ISCs and TA cells, suggesting that crypt cells might be a target of GPER. The beneficial effect of GPER was realized by protecting the crypt cells in the colitis.

We found that G-1 administration did not affect the physiologic proliferation of crypt cells, although the number of Ki67positive cells in the crypt showed an increasing trend. This reminded the protective effect of GPER on crypt cell might achieved by interfering with colitis related pathologic processes rather than direct proliferative effect on crypt cell. Enlarged ERS not only induced the apoptosis of epithelial cells but also damaged proliferation of ISCs and the regeneration of intestinal epithelial cells (Liu et al., 2018).
Thus, we established an in vitro ERS model to explore whether there was a causal relationship between inhibiting ERS and protecting crypt cells induced by GPER activation. As in vivo, G-1 decreased the upregulation of GRP78 and CHOP in the TG-induced ERS model in cultured CCD841 cells. The CCK-8 test showed that ERS caused a decrease in living cells, which was inhibited by G-1, indicating that GPER activation inhibited the ERS-induced cell injury. Consistent with the change of cell number, the inhibition of cell proliferation and downregulation of cyclin D1 expression caused by ERS was inhibited by G-1 treatment, too. Combined with in vivo and vitro results, we concluded that GPER activation protected 
the crypt cells by inhibiting ERS in colitis, so as to combat mucosal barrier disruption. These findings may account for reported anti-inflammatory action of GPER in inflammatory bowel disease (Jacenik et al., 2019c).

The role of GPER has significant tissue and cell specificity and is related to physiologic and pathologic conditions. For example, GPER activation suppressed neuronal apoptosis after cerebral ischemia-reperfusion injury (Han et al., 2019) and protected against the glucotoxicity-induced death of pancreatic $\beta$-cells (Kooptiwut et al., 2014) by inhibiting ERS, whereas G-1 promoted the death of gastric and colorectal cancer cells via ERS enhancement (Liu et al., 2017; Lee et al., 2019). The proliferative effect of GPER either on colorectal cancer cells (Jacenik et al., 2019a), bovine satellite cells (Kamanga-Sollo et al., 2014), and primordial germ cells (Ge et al., 2012) or on inducing cell-cycle arrest in cancer cells (Chan et al., 2010) has been demonstrated.

In conclusion, our results have confirmed that GPER activation inhibits the apoptosis and protect proliferation of crypt cell, resulting in protection of the intestinal mucosal barrier in colitis. This protective effect was achieved by inhibiting ERS. Mucosal healing is regarded as a key therapeutic target for colitis. GPER is expected to become a new therapeutic target for colitis. However, here we have not yet explored the mechanism by which GPER activation inhibits ERS and cannot rule out whether GPER plays a role in colitis through another mechanism independent of ERS.

\section{Authorship Contributions}

Participated in research design: B. Xue, Q. Wang, C. Liu.

Conducted experiments: Q. Wang, Li, K. Liu, J. Liu, Chai, Chen, J. Wang, Ma, Zeng.

Performed data analysis: Q. Wang, J. Liu, Wen, Ming.

Wrote or contributed to the writing of the manuscript: B. Xue, Q. Wang, C. Liu

\section{References}

Adams SM and Bornemann PH (2013) Ulcerative colitis. Am Fam Physician 87: $699-705$

Araki Y, Bamba T, Mukaisho K, Kanauchi O, Ban H, Bamba S, Andoh A, Fujiyama Y, Hattori T, and Sugihara H (2012) Dextran sulfate sodium administered orally is depolymerized in the stomach and induces cell cycle arrest plus apoptosis in the colon in early mouse colitis. Oncol Rep 28:1597-1605.

Bábíčková J, Tóthová Ľ, Lengyelová E, Bartoňová A, Hodosy J, Gardlík R, and Celec $\mathrm{P}$ (2015) Sex differences in experimentally induced colitis in mice: a role for estrogens. Inflammation 38:1996-2006.

Baldin V, Lukas J, Marcote MJ, Pagano M, and Draetta G (1993) Cyclin D1 is a nuclear protein required for cell cycle progression in G1. Genes Dev 7:812-821.

Barker N (2014) Adult intestinal stem cells: critical drivers of epithelial homeostasis and regeneration. Nat Rev Mol Cell Biol 15:19-33.

Barker N, van Es JH, Kuipers J, Kujala P, van den Born M, Cozijnsen M, Haegebarth A, Korving J, Begthel H, Peters PJ, et al. (2007) Identification of stem cells in small intestine and colon by marker gene Lgr5. Nature 449:1003-1007.

Bernstein CN (2015) Treatment of IBD: where we are and where we are going. Am $J$ Gastroenterol 110:114-126.

Bernstein CN, Wajda A, Svenson LW, MacKenzie A, Koehoorn M, Jackson M, Fedorak R, Israel D, and Blanchard JF (2006) The epidemiology of inflammatory bowel disease in Canada: a population-based study. Am J Gastroenterol 101 $1559-1568$

Bogaert S, De Vos M, Olievier K, Peeters H, Elewaut D, Lambrecht B, Pouliot P, and Laukens D (2011) Involvement of endoplasmic reticulum stress in in flammatory bowel disease: a different implication for colonic and ileal disease? PLoS One 6:e25589.

Cao SS (2016) Epithelial ER stress in crohn's disease and ulcerative colitis. Inflamm Bowel Dis 22:984-993.

Chai S, Liu K, Feng W, Liu T, Wang Q, Zhou R, Chen S, Wang L, Chen G, Ming T, et al. (2019) Activation of $\mathrm{G}$ protein-coupled estrogen receptor protects intestine from ischemia/reperfusion injury in mice by protecting the crypt cell proliferation. Clin Sci (Lond) 133:449-464.

Chan QK, Lam HM, Ng CF, Lee AY, Chan ES, Ng HK, Ho SM, and Lau KM (2010) Activation of GPR30 inhibits the growth of prostate cancer cells through sustained activation of Erk1/2, c-jun/c-fos-dependent upregulation of $\mathrm{p} 21$, and induction of G(2) cell-cycle arrest. Cell Death Differ 17:1511-1523.

Cheng SB, Dong J, Pang Y, LaRocca J, Hixon M, Thomas P, and Filardo EJ (2014) Anatomical location and redistribution of $\mathrm{G}$ protein-coupled estrogen receptor-1 during the estrus cycle in mouse kidney and specific binding to estrogens but not aldosterone. Mol Cell Endocrinol 382:950-959.

Deng F, Peng L, Li Z, Tan G, Liang E, Chen S, Zhao X, and Zhi F (2018) YAP triggers the Wnt/ $\beta$-catenin signalling pathway and promotes enterocyte selfrenewal, regeneration and tumorigenesis after DSS-induced injury. Cell Death Dis 9:153.

Désir-Vigné A, Haure-Mirande V, de Coppet P, Darmaun D, Le Dréan G, and Segain JP (2018) Perinatal supplementation of 4-phenylbutyrate and glutamine attenuates endoplasmic reticulum stress and improves colonic epithelial barrier function in rats born with intrauterine growth restriction. J Nutr Biochem 55:104-112.

Dirisina R, Katzman RB, Goretsky T, Managlia E, Mittal N, Williams DB, Qiu W, Yu J, Chandel NS, Zhang L, et al. (2011) p53 and PUMA independently regulate apoptosis of intestinal epithelial cells in patients and mice with colitis. Gastroenterology 141:1036-1045.

Fink MP and Delude RL (2005) Epithelial barrier dysfunction: a unifying theme to explain the pathogenesis of multiple organ dysfunction at the cellular level. Crit Care Clin 21:177-196.

Ge C, Yu M, and Zhang C (2012) G protein-coupled receptor 30 mediates estrogeninduced proliferation of primordial germ cells via EGFR/Akt/ß-catenin signaling pathway. Endocrinology 153:3504-3516.

Goodman WA, Havran HL, Quereshy HA, Kuang S, De Salvo C, and Pizarro TT (2017) Estrogen receptor $\alpha$ loss-of-function protects female mice from DSS-induced experimental colitis. Cell Mol Gastroenterol Hepatol 5:630-633.e1.

Han ZW, Chang YC, Zhou Y, Zhang H, Chen L, Zhang Y, Si JQ, and Li L (2019) GPER agonist G1 suppresses neuronal apoptosis mediated by endoplasmic reticulum stress after cerebral ischemia/reperfusion injury. Neural Regen Res 14: $1221-1229$

Harnish DC, Albert LM, Leathurby Y, Eckert AM, Ciarletta A, Kasaian M, and Keith $\mathrm{JC} \mathrm{Jr}$ (2004) Beneficial effects of estrogen treatment in the HLA-B27 transgenic rat model of inflammatory bowel disease. Am J Physiol Gastrointest Liver Physiol 286: G118-G125.

Hausmann M, Obermeier F, Paper DH, Balan K, Dunger N, Menzel K, Falk W, Schoelmerich J, Herfarth H, and Rogler G (2007) In vivo treatment with the herbal phenylethanoid acteoside ameliorates intestinal inflammation in dextran sulphate sodium-induced colitis. Clin Exp Immunol 148:373-381.

Iwamoto M, Koji T, Makiyama K, Kobayashi N, and Nakane PK (1996) Apoptosis of crypt epithelial cells in ulcerative colitis. J Pathol 180:152-159.

Jacenik D, Beswick EJ, Krajewska WM, and Prossnitz ER (2019a) G protein-coupled estrogen receptor in colon function, immune regulation and carcinogenesis. World $J$ Gastroenterol 25:4092-4104.

Jacenik D, Cygankiewicz AI, Mokrowiecka A, Małecka-Panas E, Fichna J, and Krajewska WM (2019b) Sex- and age-related estrogen signaling alteration in inflammatory bowel diseases: modulatory role of estrogen receptors. Int J Mol Sci $\mathbf{2 0} \cdot 3175$

Jacenik D, Zielińska M, Mokrowiecka A, Michlewska S, Małecka-Panas E, Kordek R, Fichna J, and Krajewska WM (2019c) G protein-coupled estrogen receptor mediates anti-inflammatory action in Crohn's disease. Sci Rep 9:6749.

Johansson M and Persson JL (2008) Cancer therapy: targeting cell cycle regulators. Anticancer Agents Med Chem 8:723-731.

Kamanga-Sollo E, Thornton KJ, White ME, and Dayton WR (2014) Role of G proteincoupled estrogen receptor-1, matrix metalloproteinases 2 and 9 , and heparin binding epidermal growth factor-like growth factor in estradiol-17ß-stimulated bovine satellite cell proliferation. Domest Anim Endocrinol 49:20-26.

Kane SV and Reddy D (2008) Hormonal replacement therapy after menopause is protective of disease activity in women with inflammatory bowel disease. Am $J$ Gastroenterol 103:1193-1196.

Kaser A and Blumberg RS (2010) Endoplasmic reticulum stress and intestinal inflammation. Mucosal Immunol 3:11-16.

Kaser A, Martínez-Naves E, and Blumberg RS (2010) Endoplasmic reticulum stress: implications for inflammatory bowel disease pathogenesis. Curr Opin Gastroenterol 26:318-326.

Khalili H, Higuchi LM, Ananthakrishnan AN, Manson JE, Feskanich D, Richter JM, Fuchs CS, and Chan AT (2012) Hormone therapy increases risk of ulcerative colitis but not Crohn's disease. Gastroenterology 143:1199-1206.

Kooptiwut S, Mahawong P, Hanchang W, Semprasert N, Kaewin S, Limjindaporn T, and Yenchitsomanus PT (2014) Estrogen reduces endoplasmic reticulum stress to protect against glucotoxicity induced-pancreatic $\beta$-cell death. J Steroid Biochem Mol Biol 139:25-32.

Kraft CL, Rappaport JA, Snook AE, Pattison AM, Lynch JP, and Waldman SA (2017) GUCY2C maintains intestinal LGR5 ${ }^{+}$stem cells by opposing ER stress. Oncotarget 8:102923-102933.

Kumral ZN, Memi G, Ercan F, and Yeğen BC (2014) Estrogen alleviates acetic acidinduced gastric or colonic damage via both ER $\alpha$ - and ER $\beta$-mediated and direct antioxidant mechanisms in rats. Inflammation 37:694-705.

Lee SJ, Kim TW, Park GL, Hwang YS, Cho HJ, Kim JT, and Lee HG (2019) G protein-coupled estrogen receptor-1 agonist induces chemotherapeutic effect via ER stress signaling in gastric cancer. BMB Rep 52:647-652.

Li Y, Xu J, Jiang F, Jiang Z, Liu C, Li L, Luo Y, Lu R, Mu Y, Liu Y, et al. (2016) G protein-coupled estrogen receptor is involved in modulating colonic motor function via nitric oxide release in C57BL/6 female mice. Neurogastroenterol Motil 28 $432-442$

Liu Q, Chen Z, Jiang G, Zhou Y, Yang X, Huang H, Liu H, Du J, and Wang H (2017) Epigenetic down regulation of $\mathrm{G}$ protein-coupled estrogen receptor (GPER) functions as a tumor suppressor in colorectal cancer. Mol Cancer 16:87.

Liu R, Li X, Huang Z, Zhao D, Ganesh BS, Lai G, Pandak WM, Hylemon PB, Bajaj JS, Sanyal AJ, et al. (2018) C/EBP homologous protein-induced loss of intestinal epithelial stemness contributes to bile duct ligation-induced cholestatic liver injury in mice. Hepatology 67:1441-1457.

Lu D, Qu Y, Shi F, Feng D, Tao K, Gao G, He S, and Zhao T (2016) Activation of G protein-coupled estrogen receptor 1 (GPER-1) ameliorates blood-brain barrier 
permeability after global cerebral ischemia in ovariectomized rats. Biochem Biophys Res Commun 477:209-214.

Ma X, Sun Q, Sun X, Chen D, Wei C, Yu X, Liu C, Li Y, and Li J (2018) Activation of $\mathrm{GABA}_{\mathrm{A}}$ receptors in colon epithelium exacerbates acute colitis. Front Immunol 9:987. McGuckin MA, Eri RD, Das I, Lourie R, and Florin TH (2010) ER stress and the unfolded protein response in intestinal inflammation. Am J Physiol Gastrointest Liver Physiol 298:G820-G832.

McGuckin MA, Eri RD, Das I, Lourie R, and Florin TH (2011) Intestinal secretory cell ER stress and inflammation. Biochem Soc Trans 39:1081-1085.

Mohammad I, Starskaia I, Nagy T, Guo J, Yatkin E, Väänänen K, Watford WT, and Chen $\mathrm{Z}$ (2018) Estrogen receptor $\alpha$ contributes to T cell-mediated autoimmune inflammation by promoting T cell activation and proliferation. Sci Signal 11:eaap9415.

Ng SC, Shi HY, Hamidi N, Underwood FE, Tang W, Benchimol EI, Panaccione R, Ghosh S, Wu JCY, Chan FKL, et al. (2018) Worldwide incidence and prevalence of inflammatory bowel disease in the 21st century: a systematic review of populationbased studies. Lancet 390:2769-2778.

Oyadomari S and Mori M (2004) Roles of CHOP/GADD153 in endoplasmic reticulum stress. Cell Death Differ 11:381-389.

Prossnitz ER and Barton M (2014) Estrogen biology: new insights into GPER function and clinical opportunities. Mol Cell Endocrinol 389:71-83.

Revankar CM, Cimino DF, Sklar LA, Arterburn JB, and Prossnitz ER (2005) A transmembrane intracellular estrogen receptor mediates rapid cell signaling. Science 307:1625-1630.

Saleiro D, Murillo G, Benya RV, Bissonnette M, Hart J, and Mehta RG (2012) Estrogen receptor- $\beta$ protects against colitis-associated neoplasia in mice. Int $J$ Cancer 131:2553-2561.

Spary EJ, Chapman SE, Sinfield JK, Maqbool A, Kaye J, and Batten TF (2013) Novel G protein-coupled oestrogen receptor GPR30 shows changes in mRNA expression in the rat brain over the oestrous cycle. Neurosignals 21:14-27.

Su L, Nalle SC, Shen L, Turner ES, Singh G, Breskin LA, Khramtsova EA Khramtsova G, Tsai PY, Fu YX, et al. (2013) TNFR2 activates MLCK-dependent tight junction dysregulation to cause apoptosis-mediated barrier loss and experimental colitis. Gastroenterology 145:407-415.
Tabas I and Ron D (2011) Integrating the mechanisms of apoptosis induced by endoplasmic reticulum stress. Nat Cell Biol 13:184-190.

Takagi T, Homma T, Fujii J, Shirasawa N, Yoriki H, Hotta Y, Higashimura Y, Mizushima K, Hirai Y, Katada K, et al. (2019) Elevated ER stress exacerbates dextran sulfate sodium-induced colitis in PRDX4-knockout mice. Free Radic Biol Med 134:153-164.

Turner JR (2009) Intestinal mucosal barrier function in health and disease. Nat Rev Immunol 9:799-809.

van der Giessen J, van der Woude CJ, Peppelenbosch MP, and Fuhler GM (2019) A direct effect of sex hormones on epithelial barrier function in inflammatory bowel disease models. Cells 8:261.

Vo DH, Hartig R, Weinert S, Haybaeck J, and Nass N (2019) G-Protein-Coupled estrogen receptor (GPER)-specific agonist G1 induces ER stress leading to cell death in MCF-7 cells. Biomolecules 9:503.

Wada-Hiraike O, Imamov O, Hiraike H, Hultenby K, Schwend T, Omoto Y, Warner M, and Gustafsson JA (2006) Role of estrogen receptor beta in colonic epithelium. Proc Natl Acad Sci USA 103:2959-2964.

Włodarczyk M, Sobolewska-Włodarczyk A, Cygankiewicz AI, Jacenik D, PiechotaPolańczyk A, Stec-Michalska K, Krajewska WM, Fichna J, and Wiśniewska-Jarosińska M (2017) G protein-coupled receptor 30 (GPR30) expression pattern in inflammatory bowel disease patients suggests its key role in the inflammatory process. A preliminary study. J Gastrointestin Liver Dis 26:29-35.

Wu X, Sun L, Zha W, Studer E, Gurley E, Chen L, Wang X, Hylemon PB, Pandak WM Jr, Sanyal AJ, et al. (2010) HIV protease inhibitors induce endoplasmic reticulum stress and disrupt barrier integrity in intestinal epithelial cells. Gastroenterology 138:197-209.

Address correspondence to: Dr. Bing Xue, Department of Physiology and Pathohysiology, School of Basic Medical Science, Cheeloo College of Medicine, Shandong University, 44 Wenhuaxi Rd., Jinan, Shandong, 250012, China. E-mail: xuebing@sdu.edu.cn 